\title{
Mental Health Status among Married Working Women Residing in Bhubaneswar City, India: A Psychosocial Survey
}

\author{
Ansuman Panigrahi, Aditya Prasad Padhy, and Madhulita Panigrahi \\ Department of Community Medicine, Kalinga Institute of Medical Sciences, KIIT University, Campus-5, Bhubaneswar, Odisha 751024, \\ India \\ Correspondence should be addressed to Ansuman Panigrahi; dr.ansuman3@gmail.com
}

Received 4 February 2014; Accepted 14 February 2014; Published 31 March 2014

Academic Editor: Antonella Gigantesco

Copyright (C) 2014 Ansuman Panigrahi et al. This is an open access article distributed under the Creative Commons Attribution License, which permits unrestricted use, distribution, and reproduction in any medium, provided the original work is properly cited.

\begin{abstract}
Mental health is a major public health concern worldwide. This study aimed to assess the mental health status and its correlates among married working women residing in Bhubaneswar city of Odisha, India. A cross-sectional study was undertaken in 240 households involving 240 married working women following a multistage cluster random sampling design. Using the predesigned, pretested interview schedule and self-reporting questionnaire, all relevant information was collected. Our study revealed that $32.9 \%$ of study respondents had poor mental health and only about $10 \%$ of these women had sought any kind of mental health services. Logistic regression analysis showed that 3 predictors such as favourable attitude of colleagues, sharing their own problems with husband, and spending time for yoga/meditation/exercise had significant positive impact on the mental health status of married working women. A preventive program regarding various aspects of mental health for married working women at workplace as well as community level could be a useful strategy in reducing this public health problem.
\end{abstract}

\section{Introduction}

Mental health is one of the most important public health issues as it is a major contributor (14\%) to the global burden of disease worldwide [1]. It means the ability to respond to diverse experiences of life with flexibility and a sense of purpose. It can be described as a state of balance between an individual and his surrounding world, a state of harmony between oneself and others [2]. Mental health is the foundation for well-being and effective functioning for an individual and for a community and that of women is important both for their own health and for the well-being of their children and families. Women are more likely than men to be adversely affected by mental disorders, the most common being anxiety and depressive disorders $[3,4]$.

Status of women in the society has been changing fast due to multiple factors such as urbanization, industrialization, increased level of education, awareness of rights, and media influence. More and more women prefer to be engaged in some kind of employment, so that they can contribute financially to their family. But the attitude towards women especially married women and their role in family has remained the same, as even today taking care of the family and children is considered as their primary responsibility. Thus carrying out duties and responsibilities both at home and workplace overstrains a married working woman, thereby leading to various psychological problems like role conflict, job strain, mental fatigue, stress, anxiety, frustration, depression, anger, phobias, and other social and emotional distress. All of these problems can interactively affect the mental well-being of working women and more so in married working women. Studies have shown that working women have poor mental health and higher level of depression compared to nonworking women [5]. Data on mental health among married working women in India is sparse and to the authors' knowledge there has been no such study conducted in the state of Odisha.

In this context, the present study was planned to be undertaken in Bhubaneswar city to assess the mental health status among married working women and their role perception and determine the mental health correlates, so that appropriate targets for interventions could be identified. 


\section{Materials and Methods}

Bhubaneswar, the capital city of the state of Odisha, is situated at the intersection of $20^{\circ} 12^{\prime} \mathrm{N}-20^{\circ} 25^{\prime} \mathrm{N}$ latitude and $85^{\circ} 44^{\prime} \mathrm{E}-$ $85^{\circ} 55^{\prime} \mathrm{E}$ longitude, 45 meters above sea level. It is located southwest of the rivers Mahanadi, Baitarani, and Brahmani on the western fringe of the mid-coastal plain. Bhubaneswar includes 60 wards with a population of about 8, 50,000.

The present cross-sectional study was undertaken in the selected nonslum areas during 2011-2012. Considering the prevalence of poor mental health among women of reproductive age group as $23 \%$ observed in an Indian study [6], precision as $10 \%$, design effect as 3 , and level of confidence at 95\%, sample size was calculated as 204 . Multistage cluster random sampling design was used to select the study population. Out of total 60 wards, $20 \%$ of wards, that is, 12 wards, were selected using simple random sampling technique. From each ward, one nonslum area was randomly selected and thus in total, 12 areas were chosen as clusters for the study purpose. In each selected study area, 20 households were recruited as study units using simple random sampling technique. Only married women in the age group of 20-49 years willing to participate were considered for the study purpose whereas nonvolunteers, pregnant women, and those having any known health disorder were excluded from the study. In case of presence of two or more study subjects in one household, only one respondent was randomly chosen and if no woman was found in the selected household, the next adjacent household was approached. Overall, 240 eligible willing women from 240 households were recruited as study subjects and interviewed after obtaining the informed consent keeping their identities anonymous. However, 24 women could not continue in the study till the end and thus finally 216 married working women were considered as study participants. Using the predesigned and pretested interview schedule, all relevant information regarding sociodemographic characteristics like age, education, occupation, income, addiction, and so forth, was collected. Also perception of women respondents regarding home situation, family, and social issues was assessed.

The self-reporting questionnaire (SRQ), a standardized instrument, was administered to measure the mental health status of the participating women. This is a 20 -item questionnaire requiring yes/no responses and screens for the presence of anxiety and depressive disorders. The SRQ has been standardised in India in two separate studies $[7,8]$. Patients who scored 7 or more on the SRQ were designated as having poor mental health and those with a score below 7 were designated as being normal. Women found to have poor mental health were counselled and referred to nearby health facility for further investigation and follow-up.

Analyses. Statistical procedures such as simple descriptive statistics (means, standard deviations, and proportions), measure of association like chi-square test, and binary logistic regression models were employed for the data analysis. The logistic regression coefficients (log odds) and exponential of these values, that is, the odds in favour of poor mental health, were derived from logistic regression model which represents
TABLE 1: Mental health status of married working women $(N=216)$.

\begin{tabular}{lc}
\hline Variables & Number (\%) \\
\hline Mental health status & $71(32.9)$ \\
Poor & $145(67.1)$ \\
Normal & \\
Sought mental health services before & $07(9.8)$ \\
Yes & $64(91.2)$ \\
No
\end{tabular}

the risk of outcome associated with category of independent variables. All analyses were performed with SPSS statistical software version 16.0.

\section{Results}

Table 1 depicts the mental health status of married working women. It was observed that nearly one-third of women had poor mental health outcome and only about 7 (9.8\%) of them sought mental health services in public/private health care facilities during the last one year.

Mean age of the study population was found to be $34.02 \pm$ 7.23 years. About three-fourths of the respondents were more than 30 years old. Out of 216 married working women, 175 ( $81 \%)$ belonged to nuclear family. More than half of women belonged to general caste and the rest were from other backward caste (OBC), scheduled caste (SC), and scheduled tribe (ST). Majority ( $84.2 \%)$ of study population had attained graduation and/or postgraduation. Almost half of the respondents were doing job in private organisation. Around 70\% women had denied that their husbands were addicted to alcohol or any drug. In 77 households, monthly income was >rupees 15,000/- and 41 households had monthly income <rupees 5000/-. Considering parental status, 176 (81.5\%) women had children. We observed that $16(7.4 \%)$ women reported they had been exposed to psychological trauma during last year and $33(15.3 \%)$ informed that any of her family members was chronically ill for at least one month during last 6 months. Bivariate analysis shows that younger age, addiction of husband to alcohol/drug, and presence of chronic illness among family members are significantly associated with poor mental health outcomes of married working women (Table 2).

It is evident from Table 3 that the primary reasons for taking up employment by married women were personal interest (45.4\%) followed by financial constraint (38.2\%) and husband's will (23.8\%). Around two-thirds of women had started their career before marriage. Workplace atmosphere was conducive according to $152(70.4 \%)$ respondents and more than $80 \%$ of women agreed that attitude of colleagues and husband/in-laws was favourable both at workplace and home, respectively. However, 94 (43.5\%) study subjects told that their family members expected them to do the same work as nonworking women. Nearly $90 \%$ of women denied any kind of misunderstandings or quarrels with their husband over the use of their money and almost $85 \%$ women shared their own problems with their husband. Bivariate analysis 
TABLE 2: Sociodemographic characteristics and bivariate associations with mental health outcomes among married working women.

\begin{tabular}{|c|c|c|c|}
\hline \multirow{2}{*}{ Variables } & \multicolumn{3}{|c|}{ Mental health status } \\
\hline & Poor $(\%)$ & Normal (\%) & $\chi^{2}, \mathrm{df}, P$ \\
\hline \multicolumn{4}{|l|}{ Age group (in years) } \\
\hline $20-30$ & $26(38.8)$ & $41(61.2)$ & \multirow{3}{*}{$6.339,2,0.042$} \\
\hline $31-40$ & $35(36.5)$ & $61(63.5)$ & \\
\hline $41-50$ & $10(18.9)$ & $43(81.1)$ & \\
\hline \multicolumn{4}{|l|}{ Family type } \\
\hline Joint & $60(34.3)$ & $115(65.7)$ & \multirow{2}{*}{$0.837,1,0.360$} \\
\hline Nuclear & $11(26.8)$ & $30(73.2)$ & \\
\hline \multicolumn{4}{|l|}{ Caste } \\
\hline General & $36(31.6)$ & $78(68.4)$ & \multirow{3}{*}{$0.745,2,0.689$} \\
\hline OBC & $26(36.6)$ & $45(63.4)$ & \\
\hline $\mathrm{SC} / \mathrm{ST}$ & $09(29.0)$ & $22(71.0)$ & \\
\hline \multicolumn{4}{|l|}{ Educational status } \\
\hline Intermediate & $11(32.4)$ & $23(67.6)$ & \multirow{3}{*}{$0.038,2,0.981$} \\
\hline Graduate & $43(32.6)$ & $89(67.4)$ & \\
\hline Postgraduate & $17(34.0)$ & $33(66.0)$ & \\
\hline \multicolumn{4}{|l|}{ Occupational status } \\
\hline Government & $27(29.0)$ & $66(71.0)$ & \multirow{3}{*}{$1.092,2,0.579$} \\
\hline Semigovernment & $06(35.3)$ & $11(64.7)$ & \\
\hline Private & $38(35.8)$ & $68(64.2)$ & \\
\hline \multicolumn{4}{|c|}{ Addiction of husband to alcohol/drugs } \\
\hline Yes & $28(43.1)$ & $37(56.9)$ & \multirow{2}{*}{$4.390,1,0.036$} \\
\hline No & $43(28.5)$ & $108(71.5)$ & \\
\hline \multicolumn{4}{|l|}{ Monthly income } \\
\hline$<$ Rs. 5,000 & $18(43.9)$ & $23(56.1)$ & \multirow{3}{*}{$2.840,2,0.242$} \\
\hline Rs. $5,000-15,000$ & $29(29.6)$ & $69(70.4)$ & \\
\hline$>$ Rs. 15,000 & $24(31.2)$ & $53(68.8)$ & \\
\hline \multicolumn{4}{|l|}{ Parental status } \\
\hline Had child & $55(31.2)$ & $121(68.8)$ & \multirow{2}{*}{$1.131,1,0.288$} \\
\hline Had no child & $16(40.0)$ & $24(60.0)$ & \\
\hline \multicolumn{4}{|c|}{ History of previous trauma } \\
\hline Yes & $07(43.8)$ & $09(56.2)$ & \multirow{2}{*}{$0.927,1,0.336$} \\
\hline No & $64(32.0)$ & $136(68.0)$ & \\
\hline \multicolumn{4}{|c|}{ Presence of chronic illness among family members } \\
\hline Yes & $16(48.5)$ & $17(51.5)$ & \multirow{2}{*}{$4.304,1,0.038$} \\
\hline No & $55(30.1)$ & $128(69.9)$ & \\
\hline
\end{tabular}

shows that conducive atmosphere at workplace, favourable attitude of colleagues and husband/in-laws, and sharing their own problems with husband have significant positive impact on mental health outcomes of married working women.

Table 4 explores various family/social issues and their association with mental health outcomes. More than onethird of women experienced conflict between home and job responsibilities and almost $80 \%$ had the view that they were doing justice to both roles. $178(82.4 \%)$ women said that they were participating in decision making process of family and almost the same number of women felt that there was change in attitude of contemporary men whereas nearly half of respondents had the belief in natural superiority of men. Further, majority (88.9\%) of women opined that women's employment raised family/social status. About $60 \%$ of women had time to attend social obligation whereas almost $90 \%$ of women attended religious services more than once in a month. Approximately $80 \%$ of women did not spend any time for yoga/meditation/exercise. Bivariate analysis illustrates that women experiencing any home-job conflict, not participating in decision making process of family, and not spending time for attending social obligation and also for yoga/meditation/exercise had poor mental health outcome.

All the variables which were found to be associated with mental health outcome in bivariate analyses were entered into the logistic regression model to predict the odds of mental health outcomes among the women respondents 
TABLE 3: Workplace and home situation and bivariate associations with mental health outcome.

\begin{tabular}{|c|c|c|c|}
\hline \multirow{2}{*}{ Variables } & \multicolumn{3}{|c|}{ Mental health status } \\
\hline & Poor (\%) & Normal (\%) & $\chi^{2}, \mathrm{df}, P$ \\
\hline \multicolumn{4}{|l|}{ Reason for working } \\
\hline Financial constraint & $29(38.2)$ & $47(61.8)$ & \multirow{3}{*}{$2.528,2,0.283$} \\
\hline Personal interest & $32(32.7)$ & $66(67.3)$ & \\
\hline Husband's will & $10(23.8)$ & $32(76.2)$ & \\
\hline \multicolumn{4}{|l|}{ Started career } \\
\hline Before marriage & $50(35.5)$ & $91(64.5)$ & \multirow{2}{*}{$1.235,1,0.266$} \\
\hline After marriage & $21(28.0)$ & $54(72.0)$ & \\
\hline \multicolumn{4}{|l|}{ Workplace atmosphere } \\
\hline Conducive & $40(26.3)$ & $112(73.7)$ & \multirow{3}{*}{$11.759,2,0.003$} \\
\hline Not conducive & $18(56.2)$ & $14(43.8)$ & \\
\hline Neutral & $13(40.6)$ & $19(59.4)$ & \\
\hline \multicolumn{4}{|l|}{ Attitude of colleagues } \\
\hline Favourable & $48(26.5)$ & $133(73.5)$ & \multirow{2}{*}{$20.419,1,0.000$} \\
\hline Unfavourable/indifferent & $23(65.7)$ & $12(34.3)$ & \\
\hline \multicolumn{4}{|l|}{ Attitude of husband/in-laws } \\
\hline Favourable & $54(29.8)$ & $127(70.2)$ & \multirow{2}{*}{$4.666,1,0.031$} \\
\hline Unfavourable/indifferent & $17(48.6)$ & $18(51.4)$ & \\
\hline \multicolumn{4}{|c|}{ Managing household affairs satisfactorily } \\
\hline Almost always & $09(25.0)$ & $27(75.0)$ & \multirow{4}{*}{$3.507,3,0.319$} \\
\hline Frequently & $20(35.1)$ & $37(64.9)$ & \\
\hline Occasionally & $28(30.4)$ & $64(69.6)$ & \\
\hline Rarely/never & $14(45.2)$ & $17(54.8)$ & \\
\hline \multicolumn{4}{|c|}{ Family members expecting same work as nonworking women } \\
\hline Yes & $30(31.9)$ & $64(68.1)$ & \multirow{2}{*}{$0.069,1,0.793$} \\
\hline No & $41(33.6)$ & $81(66.4)$ & \\
\hline \multicolumn{4}{|c|}{ Misunderstanding/quarrels with husband } \\
\hline Yes & $10(41.7)$ & $14(58.3)$ & \multirow{2}{*}{$0.947,1,0.331$} \\
\hline No & $61(31.8)$ & $131(68.2)$ & \\
\hline \multicolumn{4}{|c|}{ Sharing own problems with husband } \\
\hline Yes & $55(30.1)$ & $128(69.9)$ & \multirow{2}{*}{$4.304,1,0.038$} \\
\hline No & $16(48.5)$ & $17(51.5)$ & \\
\hline
\end{tabular}

(Table 5). It was observed that attitude of colleagues, sharing their own problems with husband, and spending time for yoga/meditation/exercise were significantly affecting the mental health status of married working women.

\section{Discussion}

In our study, we observed that the prevalence of poor mental health among married working women was $32.9 \%$ of which only about $10 \%$ of women with poor mental health had sought any kind of mental health services even though these services are available in various government and private hospitals and nursing homes including three private medical institutions established in Bhubaneswar city. This might be attributed to social stigma attached to mental disorders or lack of awareness about availability of such services. This finding highlights the urgent need for developing an effective preventive programme or improving the existing system emphasizing on provision of mental health services. Zeynep et al. found in their study that a considerable proportion (25.9\%) of women were having any mental disorder and only $4.7 \%$ had ever received care from mental health services [9]. WHO also reported that the prevalence of mental disorders of women was $25 \%$ and majority of them did not seek any mental health service [10]. Adzlin et al. showed the prevalence of psychological distress among married working women as $22.8 \%$ [11]. Another study in Ethiopia showed the prevalence of mental distress in working women as $25.9 \%$ [12]. Bivariate analysis revealed that younger married working women had poor mental health as compared to older counterparts. This could be due to the reason that younger women might be starting to handle new additional responsibilities after marriage. Further, women whose husbands were addicted to alcohol or any drug and women who had family members suffering from chronic illness were found to be at increased risk of developing poor mental health. Various other studies also supported these findings [6, 12-14]. 
TABLE 4: Family/social issues and bivariate associations with mental health outcomes.

\begin{tabular}{|c|c|c|c|}
\hline \multirow{2}{*}{ Variables } & \multicolumn{3}{|c|}{ Mental health status } \\
\hline & Poor $(\%)$ & Normal (\%) & $\chi^{2}$, df, $P$ \\
\hline \multicolumn{4}{|c|}{ Experiencing any conflict } \\
\hline Yes & $36(42.9)$ & $48(57.1)$ & \multirow{2}{*}{$6.213,1,0.013$} \\
\hline No & $35(26.5)$ & $97(73.5)$ & \\
\hline \multicolumn{4}{|c|}{ Doing justice to both roles } \\
\hline Yes & $52(30.4)$ & $119(69.6)$ & \multirow{2}{*}{$2.253,1,0.133$} \\
\hline No & $19(42.2)$ & $26(57.8)$ & \\
\hline \multicolumn{4}{|c|}{ Participation in decision making process of family } \\
\hline Yes & $53(29.8)$ & $125(70.2)$ & \multirow{2}{*}{$4.393,1,0.036$} \\
\hline No & $18(47.4)$ & $20(52.6)$ & \\
\hline \multicolumn{4}{|c|}{ Change in attitude of contemporary men } \\
\hline Yes & $61(33.7)$ & $120(66.3)$ & \multirow{2}{*}{$0.350,1,0.554$} \\
\hline No & $10(28.6)$ & $25(71.4)$ & \\
\hline \multicolumn{4}{|c|}{ Belief in natural superiority of men } \\
\hline Yes & $30(30.0)$ & $70(70.0)$ & \multirow{2}{*}{$0.695,1,0.404$} \\
\hline No & $41(35.3)$ & $75(64.7)$ & \\
\hline \multicolumn{4}{|c|}{ Women's employment raising family/social status } \\
\hline Yes & $63(32.8)$ & $129(67.2)$ & \multirow{2}{*}{$0.003,1,0.959$} \\
\hline No & $08(33.8)$ & $16(66.7)$ & \\
\hline \multicolumn{4}{|c|}{ Time for attending social obligation } \\
\hline Yes & $34(26.6)$ & $94(73.4)$ & \multirow{2}{*}{$5.665,1,0.017$} \\
\hline No & $37(42.0)$ & $51(58.0)$ & \\
\hline \multicolumn{4}{|c|}{ Attending religious services } \\
\hline 0-1 time/month & $62(32.5)$ & $129(67.5)$ & \multirow{2}{*}{$0.125,1,0.723$} \\
\hline$>1$ time/month & $09(36.0)$ & $16(64.0)$ & \\
\hline \multicolumn{4}{|c|}{ Spending time for yoga/meditation/exercise } \\
\hline Nil & $63(36.8)$ & $108(63.2)$ & \multirow{3}{*}{$6.652,2,0.036$} \\
\hline 1-2 times/week & $06(23.1)$ & $20(76.9)$ & \\
\hline$>2$ times/week & $02(10.5)$ & $17(89.5)$ & \\
\hline
\end{tabular}

Home and workplace atmosphere played a major role in deciding the mental health status of married working women. Conducive workplace atmosphere, favourable attitude of colleagues at workplace, and favourable attitudes of husbands/in-laws at home were found to be protective of overall mental health. Kopp et al. established in their study that job related factors and social support from family were important predictors of mental health [15]. Women who were sharing their own problems with their husbands had maintained good mental health. In addition, we found that some family/social issues like those women who experienced jobfamily conflict or did not participate in decision making process of family were at increased risk of developing poor mental health whereas spending time to attend social obligations and devoting some time for yoga/meditation/exercise had good mental health outcome. Chandola et al. observed that both work-to-family and family-to-work conflict affected the mental health of men and women in three different countries [16].

Logistic regression model identified 3 important predictors of poor mental health outcome among married working women. We observed that women experiencing favourable attitude of their colleagues at workplace were about 4.5 times more likely to have normal mental health as compared to women who were facing an unfavourable or indifferent attitude of their colleagues. The likelihood of normal mental health rises about 4 times when women were sharing their problems with husbands versus women not doing so. Further, women who were not engaged in any yoga/medication/exercise had almost 7 times more chance of developing poor mental health as compared to women engaged in yoga/medication/exercise more than 2 times per week. These findings indicate that there should be sincere effort at workplaces in building healthy relationship among employees, thereby developing favourable attitude of colleagues towards each other which will help in maintaining good mental health, especially, of women employees. Also at family level, working women and their husbands must be counselled regarding the relevance of sharing their own problems with each other as it will not only help them find viable solutions for their problems but also prevent developing poor mental health. Community based orientation programs regarding various aspects of mental health should be organized at regular intervals for the working 
TABLE 5: Results of binary logistic regression predicting the odds of mental health outcomes among women respondents $(N=216)$.

\begin{tabular}{|c|c|c|c|}
\hline \multirow[t]{2}{*}{ Independent variable } & \multicolumn{2}{|c|}{ Dependent variable } & \multirow[t]{2}{*}{ " $P$ " value } \\
\hline & $(\beta)$ & $\operatorname{Exp}(\beta)$ & \\
\hline Age group (in years) & & & 0.203 \\
\hline $20-30$ & -0.816 & 0.442 & 0.104 \\
\hline $\begin{array}{l}31-40 \\
41-50^{\mathrm{R}}\end{array}$ & -0.765 & 0.466 & 0.101 \\
\hline Addiction of husband to alcohol/drugs & & & \\
\hline $\begin{array}{l}\text { Yes } \\
\mathrm{No}^{\mathrm{R}}\end{array}$ & -0.690 & 0.502 & 0.061 \\
\hline Chronic illness of family members & & & \\
\hline $\begin{array}{l}\text { Yes } \\
\mathrm{No}^{\mathrm{R}}\end{array}$ & -0.201 & 0.818 & 0.691 \\
\hline Workplace atmosphere & & & 0.152 \\
\hline Conducive & 0.735 & 2.086 & 0.115 \\
\hline $\begin{array}{l}\text { Not conducive } \\
\text { Neutral }^{\mathrm{R}}\end{array}$ & -0.054 & 0.948 & 0.933 \\
\hline Attitude of colleagues & & & \\
\hline $\begin{array}{l}\text { Favourable } \\
\text { Unfavourable/indifferent }^{\mathrm{R}}\end{array}$ & 1.520 & 4.571 & 0.004 \\
\hline Attitude of husband/in-laws & & & \\
\hline $\begin{array}{l}\text { Favourable } \\
\text { Unfavourable/indifferent }^{\mathrm{R}}\end{array}$ & 0.809 & 2.245 & 0.086 \\
\hline Sharing their own problems with husband & & & \\
\hline $\begin{array}{l}\text { Yes } \\
\mathrm{No}^{\mathrm{R}}\end{array}$ & 1.351 & 3.860 & 0.005 \\
\hline Experiencing any conflict & & & \\
\hline $\begin{array}{l}\text { Yes } \\
\mathrm{No}^{\mathrm{R}}\end{array}$ & -0.509 & 0.601 & 0.169 \\
\hline Time for social obligation & & & \\
\hline $\begin{array}{l}\text { Yes } \\
\mathrm{No}^{\mathrm{R}}\end{array}$ & 0.661 & 1.937 & 0.063 \\
\hline Spending time for yoga/meditation/exercise & & & 0.019 \\
\hline Nil & -1.932 & 0.145 & 0.018 \\
\hline $\begin{array}{l}\text { 1-2 times/week } \\
>2 \text { times/week }\end{array}$ & 0.867 & 0.420 & 0.365 \\
\hline $\begin{array}{l}\text { Participation in decision making } \\
\text { process of family }\end{array}$ & & & \\
\hline $\begin{array}{l}\text { Yes } \\
\mathrm{No}^{\mathrm{R}}\end{array}$ & 0.553 & 1.738 & 0.207 \\
\hline
\end{tabular}

Note: R: reference category; $\beta$ : regression coefficient (log odds ratio). Exp ( $\beta$ ): odds ratio. The model fit statistics were as follows. Omnibus tests of model coefficients: $\chi^{2}$ value of 62.342 with a " $P$ " value of 0.000 tells that the final model as a whole fits significantly better than an empty model (model with no predictors). Hosmer and Lemeshow test: $\chi^{2}$ value of 3.062 with a " $P$ " value of 0.930 indicates that there is no significant difference between observed and predicted probabilities and thus the model fits.

women emphasizing the beneficial effect of activities like yoga/mediation/exercise on mental health and thus they should be encouraged to incorporate such activities in their daily routine activities.

\section{Limitation and Conclusion}

The cross-sectional design of our study precluded the ability to establish the casual association between the identified independent variables and poor mental health status. This study did not include married working women more than 50 years old which decreases the generalizability of study's findings to a wider section of older women. Again as information regarding various predictive variables was based on self-reports by respondents, it may lead to response bias. Despite these limitations, the results of the study had important practical implications such as assessment of the problem among married working women and identification of risk factors/predictors of poor mental health outcome 
which can help the policy makers and health professionals in planning essential intervention strategies to deal with this social stigma. Further analytic epidemiological research is needed to replicate the findings and find out potential predictive variables.

\section{Disclosure}

The authors declare that the paper is an original work and it has not been published before or submitted for publication to another scientific journal or is being considered for publication elsewhere. They declare that the paper publication has been approved by all the coauthors.

\section{Conflict of Interests}

The authors declare that there is no conflict of interests regarding the publication of this paper.

\section{Acknowledgment}

The authors thank all the participants for their cooperation throughout the study.

\section{References}

[1] M. Prince, V. Patel, S. Saxena et al., "No health without mental health," The Lancet, vol. 370, no. 9590, pp. 859-877, 2007.

[2] K. Park, "Concept of health and disease," in Parks' Textbook of Preventive and Social Medicine, M/S Banarsidas Bhanot, 22nd edition, 2013.

[3] F. Almeida, I. Lessa, L. Magalhaes et al., "Social inequality and depressive disorders in Bahia, Brazil: interactions of gender, ethnicity, and social class," Social Science and Medicine, vol. 59, no. 7, pp. 1339-1353, 2004.

[4] A. Nurullah, "Gender differences in distress: the mediating influence of life stressors and psychological resources," Asian Social Science, vol. 6, no. 5, pp. 27-35, 2010.

[5] R. R. Dudhatra and Y. A. Jogsan, "Mental health and depression among working and non-working women," International Journal of Scientific and Research Publications, vol. 2, no. 8, 2012.

[6] S. Kumar, L. Jeyaseelan, S. Suresh, and R. C. Ahuja, "Domestic violence and its mental health correlates in Indian women," British Journal of Psychiatry, vol. 187, pp. 62-67, 2005.

[7] B. Sen, "Psychiatric phenomena in primary health healthcare, their extent and nature," Indian Journal of Psychiatry, vol. 29, pp. 33-40, 1987.

[8] T. N. Srinivasan and T. R. Suresh, "The nonspecific symptom screening method. Detection of nonpsychotic morbidity based on nonspecific symptoms," General Hospital Psychiatry, vol. 12, pp. 106-114, 1990.

[9] S. Zeynep, A. K. Dilek, A. Altindag, and M. Gunes, "Prevalence and predictors of mental disorders among women in Sanliurfa, Southeastern Turkey," Journal of Public Health, vol. 30, no. 4, pp. 487-493, 2008.

[10] World Health Organization, Women's Mental Health: An Evidence Based Review, Mental Health Determinants and Populations, Department of Mental Health and Substance Dependence, 2000.
[11] U. Adzlin, M. Marhani, A. A. Salina et al., "Prevalence of psychological distress and depressive disorders among married working women in Malaysia," Malaysian Journal of Psychiatry, vol. 20, no. 1, 2011.

[12] B. Gelaye, S. Lemma, N. Deyassa et al., "Prevalence and correlates of mental distress among working adults in Ethiopia," Clinical Practice \& Epidemiology in Mental Health, vol. 8, pp. 126-133, 2012.

[13] H. Al-Modallal, J. Abuidhail, A. Sowan, and A. Al-Rawashdeh, "Determinants of depressive symptoms in Jordanian working women," Journal of Psychiatric and Mental Health Nursing, vol. 17, no. 7, pp. 569-576, 2010.

[14] R. Shidhaye and V. Patel, "Association of socio-economic, gender and health factors with common mental disorders in women: a population-based study of 5703 married rural women in India," International Journal of Epidemiology, vol. 39, no. 6, pp. 1510-1521, 2010.

[15] M. S. Kopp, A. Stauder, G. Purebl, I. Janszky, and A. Skrabski, "Work stress and mental health in a changing society," European Journal of Public Health, vol. 18, no. 3, pp. 238-244, 2008.

[16] T. Chandola, P. Martikainen, M. Bartley et al., "Does conflict between home and work explain the effect of multiple roles on mental health? A comparative study of Finland, Japan, and the UK,' International Journal of Epidemiology, vol. 33, no. 4, pp. 884-893, 2004. 


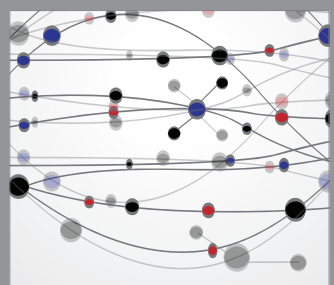

The Scientific World Journal
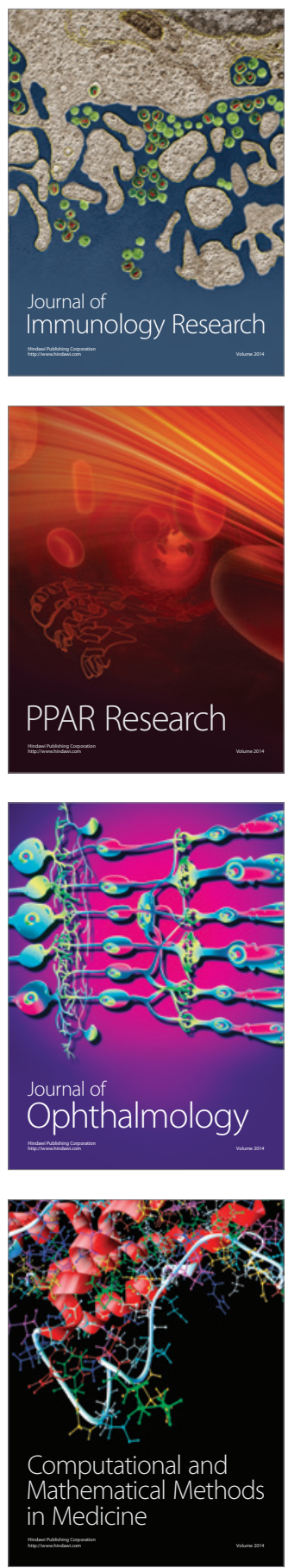

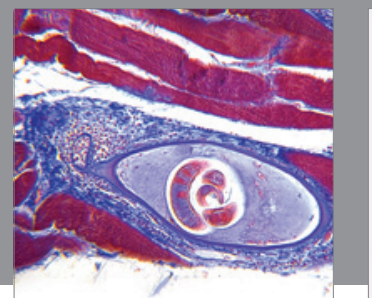

Gastroenterology

Research and Practice
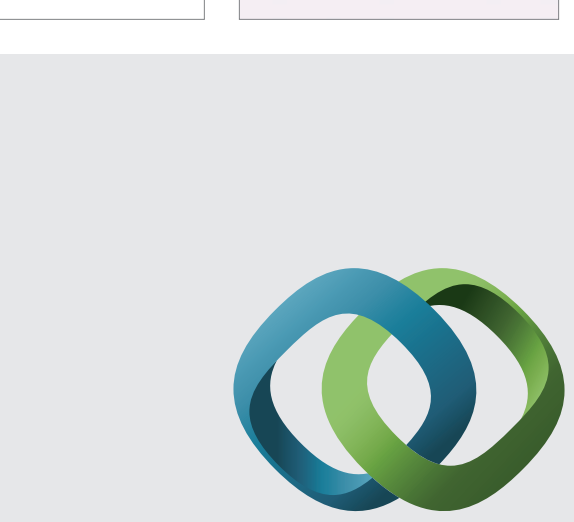

\section{Hindawi}

Submit your manuscripts at

http://www.hindawi.com
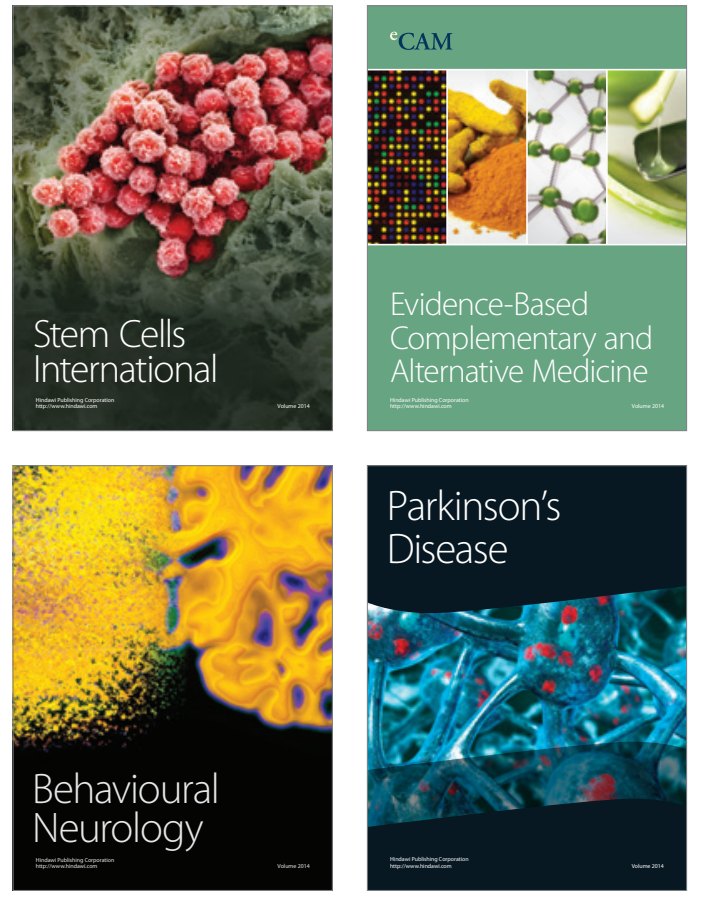
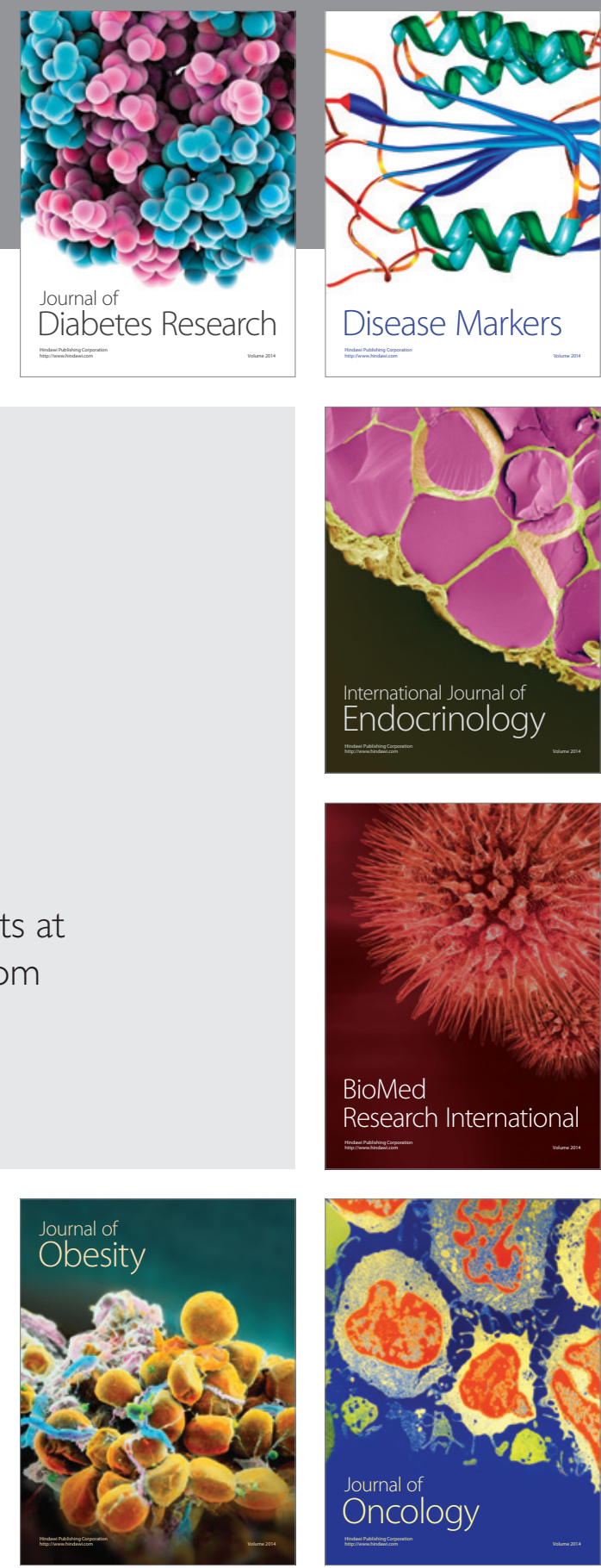

Disease Markers
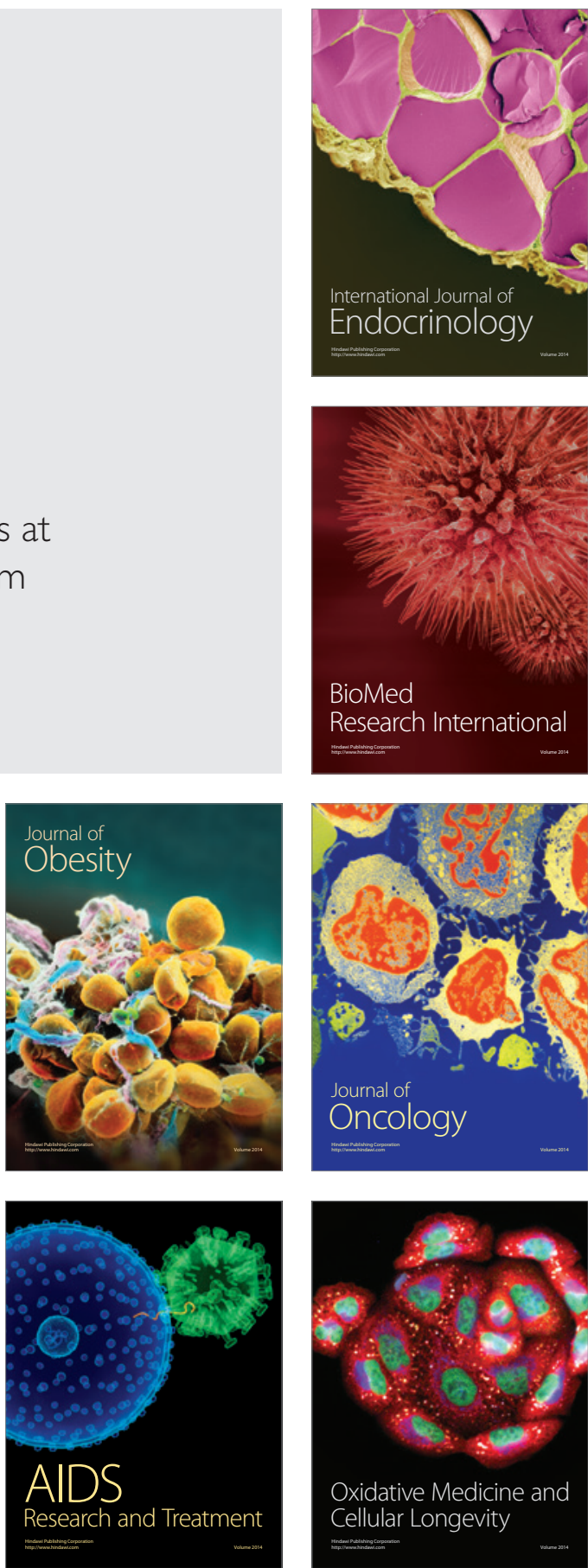